\title{
NECESSARY CONDITIONS FOR THE BOUNDEDNESS OF LINEAR AND BILINEAR COMMUTATORS ON BANACH FUNCTION SPACES
}

\author{
LuCAS ChaFFEe AND DAVID CRUZ-URIBE, OFS
}

Abstract. In this article we extend recent results by the first author [3] on the necessity of $B M O$ for the boundedness of commutators on the classical Lebesgue spaces. We generalize these results to a large class of Banach function spaces. We show that with modest assumptions on the underlying spaces and on the operator $T$, if the commutator $[b, T]$ is bounded, then the function $b$ is in $B M O$.

Mathematics subject classification (2010): 42B20, 42B35.

Keywords and phrases: BMO, commutators, singular integrals, fractional integrals, bilinear operators, weights, variable Lebesgue spaces.

\section{REFERENCES}

[1] C. Bennett And R. Sharpley, Interpolation of Operators, volume $\mathbf{1 2 9}$ of Pure and Applied Mathematics. Academic Press Inc., Boston, MA, 1988.

[2] E. I. BEREZHNOĬ, Two-weighted estimations for the Hardy-Littlewood maximal function in ideal Banachspaces, Proc. Amer. Math. Soc., 127 (1): 79-87, 1999.

[3] L. CHAFFEE, Characterizations of BMO through commutators of bilinear singular integral operators, Proc. Roy. Soc. Edinburgh Sect. A, 146 (6): 1159-1166, 2016.

[4] S. Chen AND H. Wu, Multiple weighted estimates for commutators of multilinear fractional integraloperators, Sci. China, 56 (9): 1879-1894, 2013.

[5] X. Chen And Q. XuE, Weighted estimates for a class of multilinear fractional type operators, J. Math.Anal. Appl., 362 (2): 355-373, 2010.

[6] D. CruZ-Uribe AND A. Fiorenza, Endpoint estimates and weighted norm inequalities for commutators of fractional integrals, Publ. Mat., 47 (1): 103-131, 2003.

[7] D. CruZ-Uribe And A. Fiorenza, Variable Lebesgue Spaces: Foundations and Harmonic Analysis.Applied and Numerical Harmonic Analysis, Birkhäuser, Basel, 2013.

[8] D. Cruz-Uribe, A. Fiorenza, J. M. Martell, and C. PÉrez, The boundedness of classical operators on variable $L^{p}$ spaces, Ann. Acad. Sci. Fenn. Math., 31 (1): 239-264, 2006.

[9] D. CRUZ-URIBE AND P. HÄstö, Extrapolation and interpolation in generalized Orlicz spaces, Trans. Amer. Math. Soc., to appear.

[10] D. CRUZ-URIBE AND K. MoEn, A multilinear reverse Hölder inequality with applications to multilinear weighted norm inequalities, preprint, 2017.

[11] D. CruZ-Uribe AND V. NAIBO, Kato-Ponce inequalities on weighted and variable Lebesgue spaces, Differential Integral Equations, 29 (9-10): 801-836, 2016.

[12] D. CruZ-URibe And C. J. Neugebauer, The structure of the reverse Hölder classes, Trans. Amer. Math. Soc., 347 (8): 2941-2960, 1995.

[13] D. CruZ-Uribe And L.-A. WANG, Variable Hardy spaces, Indiana Univ. Math. J., 63 (2):447-493, June2014.

[14] D. CRUZ-URIBE AND L.-A. WANG, Extrapolation and weighted norm inequalities in the variable Lebesgue spaces, Trans. Amer. Math. Soc., to appear.

[15] G. Curbera, J. García-Cuerva, J. M. Martell, and C. Peréz, Extrapolation with weights, rearrangement-invariant function spaces, modular inequalities and applications to singular integrals, Adv. Math., 203 (1): 256-318, 2006. 
[16] L. Grafakos, On multilinear fractional integrals, Studia Math., 102 (1): 49-56, 1992.

[17] L. Grafakos, Classical Fourier Analysis, volume $\mathbf{2 4 9}$ of Graduate Texts in Mathematics, Springer, New York, 2nd edition, 2008.

[18] L. Grafakos, Modern Fourier Analysis, volume 250 of Graduate Texts in Mathematics, Springer, New York, 2nd edition, 2008.

[19] L. GRAFAKOS AND N. KALton, Some remarks on multilinear maps and interpolation, Math. Ann., 319 (1): 151-180, 2001.

[20] L. Grafakos AND J. M. MARTELL, Extrapolation of weighted norm inequalities for multivariable operators and applications, J. Geom. Anal., 14 (1): 19-46, 2004.

[21] L. GRAFAKOS AND R. H. TORRES, Maximal operator and weighted norm inequalities for multilinear sin-gular integrals, Indiana Univ. Math. J., 51 (5): 1261-1276, 2002.

[22] L. Grafakos And R. H. Torres, Multilinear Calderón-Zygmund theory, Adv. Math., 165 (1): 124-164, 2002.

[23] S. JANSON, Mean oscillation and commutators of singular integral operators, Ark. Mat., 16 (1): $263-$ $270,1978$.

[24] B. JAWERTH, Weighted inequalities for maximal operators: linearization, localization and factorization, Amer. J. Math., 108 (2): 361-414, 1986.

[25] C. Kenig And E. M. Stein, Multilinear estimates and fractional integration, Math. Res. Lett., 6 (1): 1-15, 1999.

[26] V. Kokilashvili and M. Krbec, Weighted inequalities in Lorentz and Orlicz spaces, World Scientific Publishing Co. Inc., River Edge, NJ, 1991.

[27] V. KokilashVili, M. MastyŁo, AND A. Meskhi, The multisublinear maximal type operators in Banach function lattices, J. Math. Anal. Appl., 421 (1): 656-668, 2015.

[28] A. K. Lerner, S. Ombrosi, C. Pérez, R. H. Torres, and R. Trujillo-González, New maximal functions and multiple weights for the multilinear Calderón-Zygmund theory, Adv. Math., 220 (4): 1222-1264, 2009.

[29] J. Li AND B. D. Wick, Weak factorizations of the Hardy space $H^{1}\left(\mathbb{R}^{n}\right)$ in terms of multilinear Riesz transforms, preprint, 2016. arXiv:1603.02699v2.

[30] K. MoEn, Weighted inequalities for multilinear fractional integral operators, Collect. Math., 60 (2): 213-238, 2009.

[31] F. MóRICZ AND A. Veres, On the absolute convergence of multiple Fourier series, Acta Math. Hungar., 117 (3): 275-292, 2007.

[32] B. MuCKenHOUPT AND R. L. WheEdEN, Weighted norm inequalities for fractional integrals, Trans. Amer. Math. Soc., 192: 261-274, 1974.

[33] C. PÉREZ, Sharp estimates for commutators of singular integrals via iterations of the HardyLittlewood maximal function, J. Fourier Anal. Appl., 3 (6): 743-756, 1997. 